\title{
ULTRASONIC CHARACTERIZATION OF ROLLING AND RECRYSTALLIZATION TEXTURES IN ALUMINUM
}

\author{
A. J. ANDERSON ${ }^{1}$, R. B. THOMPSON ${ }^{1}$, R. BOLINGBROKE ${ }^{2}$ and J. H. ROOT ${ }^{3}$ \\ ${ }^{1}$ Ames Laboratory Iowa State University Ames, IA USA 50011 \\ ${ }^{2}$ Alcan Rolled Products Castle Works, Rogerstone Newport, Gwent NP1 9YA Wales \\ ${ }^{3}$ AECL Chalk River Laboratories Chalk River, Ontario Canada KOJ $1 J 0$
}

(Received 24 December 1995; in final form 1 April 1996)

\begin{abstract}
Crystallographic texture, which plays an important role in many forming operations, is developed during sheet metal processing. Improved product quality could be achieved if the texture could be measured, quickly and inexpensively, during different stages of the processing. One potential scheme, involving measurement of the angular dependence of the speed of ultrasonic waves propagating in the plane of the sheet is described, as applied to aluminum. While this technique has been successfully used in steel sheets, application to aluminum is more difficult because of the smaller elastic anisotropy of the crystallites. This paper presents the results of a detailed study of the strengths and weaknesses of the approach. Included are discussions of signal processing factors, the accuracy of the ultrasonically determined $\mathrm{C}_{l}^{\mu \nu}$, and a comparison between $\mathrm{C}_{l}^{\mu \nu}$ measured by ultrasonics and by diffraction techniques (both X-ray and neutron). It is found that relative velocity measurements are very good for determining $\mathrm{C}_{4}^{12}$ and $\mathrm{C}_{4}^{13}$. These measurements can easily distinguish between rolling and recrystallization textures, and can also detect more subtle variations in recrystallization textures. A systematic offset in the prediction of $\mathrm{C}_{4}^{11}$ is also reported, which is believed to be a consequence of unknown alloy dependence of the single crystal elastic constants and texture free velocities, quantities which play a key role in inferring this quantity from absolute measurements.
\end{abstract}

KEY WORDS: Ultrasonics, Aluminum, Nondestructive, Forming, Rolling Texture, Recrystallization Texture.

\section{INTRODUCTION}

Control of crystallographic texture, which strongly influences various forming operations, is an important aspect of the sheet metal production process. A first step in such control is sensing the texture that has been developed at various stages of the process. In the laboratory, $\mathrm{X}$-ray diffraction is the most familiar approach. Considerable information can be obtained in a near surface layer. Alternatively, through the oblique sectioning (or composite sample) technique, a volume average can be obtained. Similar volume average information can be obtained through neutron diffraction. However, if one desires to nondestructively obtain information in the field, e.g. at a rolling mill or can manufacturing facility, the choices are more limited. X-ray diffraction is limited to sensing a near surface layer in the commonly used reflection mode or requires quite expensive instrumentation and obtains limited information in the transmission mode. Ultrasonic measurements provide an alternate approach which, although also limited in the information that can be obtained, has the advantages of utilizing relatively simple, 
inexpensive instrumentation and sensing a volumetric average of the texture. In this paper, the use of ultrasound to characterize the rolling and recrystallization textures of hot-rolled aluminum sheet is discussed.

The process of producing aluminum sheet for can fabrication involves several steps, as illustrated in Figure 1. Usually, the process starts with a large aluminum ingot (typically, $\sim 2 \mathrm{~m} \times \sim 600 \mathrm{~mm} \times \sim 4.5 \mathrm{~m}$ ). This ingot is heated and placed into the hotrolling mill where its thickness is reduced to approximately 2.5 millimeters. Important process parameters at this stage are the temperature and speed of the sheet as it leaves the rolling operation, which controls the microstructure developed subsequent to rolling. At temperatures sufficiently above the recrystallization temperature, a well developed recrystallization texture develops after the deformation. However, if the temperature is too low, natural recrystallization may be inadequate and the sheet is coiled and annealed. In either case, the sheet is then cold-rolled to the final thickness and shipped to the can body production facility. During the cold-rolling, a deformation microstructure appears. The design goal of this processing scheme, assuming the sheet is strongly recrystallized after hot-rolling/annealing, is to cold-roll the sheet (i.e. create the deformation texture) in such a way to produce a blend of textures which will reduce earing during the can body formation (see Figure 1).

Ultrasonic wave propagation within any medium is controlled by the macroscopic elastic properties of the medium. Since the single crystal elastic constants are anisotropic, texture of a polycrystal will produce an elastic anisotropy, which will lead to an anisotropy of the velocity of ultrasonic waves. In sheet samples, measuring the angular dependence of the velocity in the plane of the sheet allows one to predict quantities that give a measure of the texture (discussed in more detail in section II).

The role of ultrasonic texture monitoring during sheet production is to nondestructively measure textures developed at various stages during the processing to assure that the desired texture is present prior to can body production. This will allow the can body makers to improve their yield. One realistic scheme is to measure the texture after hot-rolling. In times of tighter process control an on-line assessment of texture, and hence degree of recrystallization, at this stage of production would be of great benefit. Another more complex scheme would be to measure the texture on-line during the coldrolling. This on-line information could be used, in an intelligent processing sense, to control the cold-rolling parameters for optimal texture development, a process that has not yet been realized. This paper will concentrate on evaluating the degree to which ultrasonics can monitor the recrystallization after the hot roll, in support of the former potential application.

Several techniques for the ultrasonic measurement of texture have been developed over the last decade. In steel sheet, several researches have demonstrated the ability to characterize texture and use this information to predict formability parameters such as plastic strain ratios (Sayers, 1982; Cassier, Donadille, Bacroix 1989; Hirao et al., 1989; Clark Jr. et al., 1990; Borsutzki et al., 1993; Kawashima, Hyogushi, Akagi, 1993; Thompson et al., 1993). Much less work has been done in aluminum, in part because the single crystal anisotropy is considerably smaller and hence much more precise velocity measurements are required. Nevertheless, encouraging preliminary results have been obtained. In several papers by Clark Jr. (1988) and colleagues (Reno, Fields, Clark Jr., 1988) and a paper by Thompson et al. (1989), fundamental ultrasonic plate modes were used to predict texture coefficients in an expansion of the orientation distribution function (ODF). These ultrasonically determined coefficients compared favorably with values determined by $\mathrm{X}$-ray diffraction. Thompson et al., reported difficulty with one 


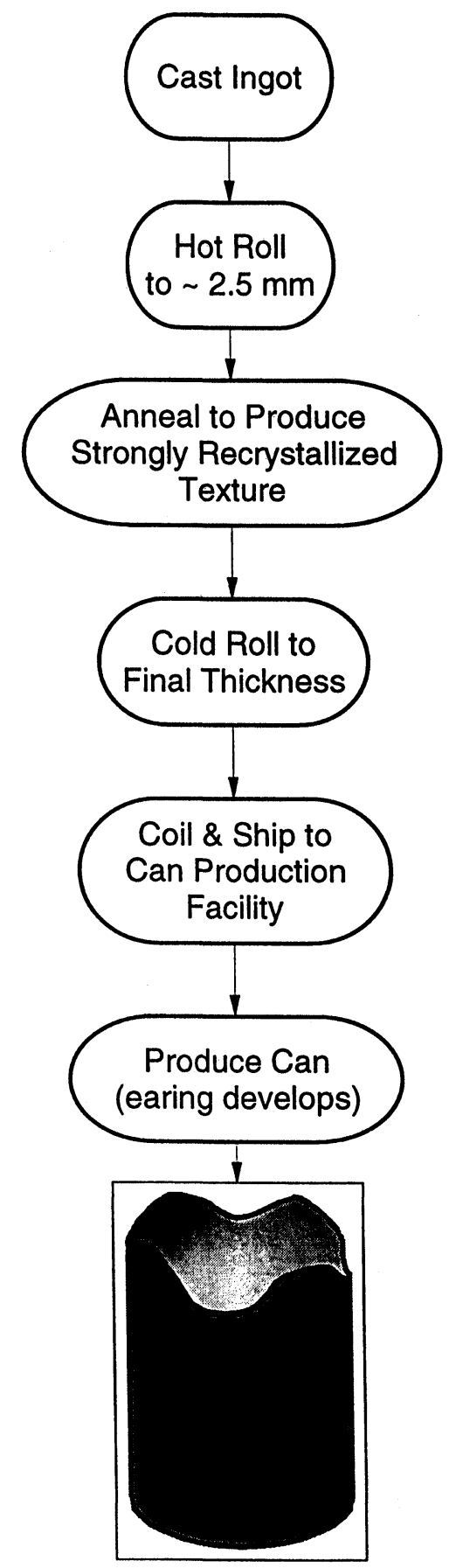

Figure 1 Flow diagram representing typical production sequence for aluminum can-body sheet. Final product shows ears formed during production of the can. 
particular texture parameter, $\mathrm{C}_{4}{ }^{11}$, but otherwise showed that ultrasonic predictions of texture parameters could be made with reasonable accuracy. Li and Thompson (1989) used higher order plate modes to predict texture parameters with much success. As a part of that study, they suggested that the difficulty with $\mathrm{C}_{4}{ }^{11}$ might be due to alloying elements in the aluminum, since predictions made on very high purity aluminum samples showed good correlation to the X-ray diffraction measurements of $\mathrm{C}_{4}{ }^{11}$, in contrast to previously reported results on alloys.

Ear formation in the final drawing procedure has been correlated to ultrasonically determined texture parameters by $\mathrm{Lu}$ et al. (Lu, Morris and Gu, 1991) and by Thompson et al (1993). Lu defined a texture parameter related to wave speed anisotropy. Thompson et al related Lu's texture parameter to the commonly used ODF coefficient, $\mathrm{C}_{4}{ }^{13}$. The combined data sets of both groups showed a strong correlation between $\mathrm{C}_{4}{ }^{13}$ and the percent earing. Thompson's conclusion was "the fact that two data sets, obtained on two different alloys made by two different manufacturers and sensed by two different wave types, fits together so nicely on a single plot suggests the existence of an underlying correlation which deserves further study." Man (1994) has provided further theoretical interpretation of this result.

The above discussion suggests that ultrasonics can predict texture parameters and that these measurements are robust and reliable. The application of these techniques to improve production of aluminum sheet is the next step. Anderson and Thompson (1994) and Stiffler, Daly and Wojnar (1994) have shown that degrees of recrystallization can be distinguished using ultrasonic predictions of texture parameters. Here, a more detailed discussion of the former work is provided.

Measurements made on two sets of samples of aluminum sheet will be presented. The first set of three sheets provided were small in physical size and measurements of the texture parameters were made by hand. The samples differed in the type of texture present, two samples were recrystallized to different degrees, and one sample was not recrystallized, i.e. contained the deformation textures. The ultrasonic measurements easily differentiated these textures. The second set of three sheets had more subtle differences, being recrystallized to varying degrees. As the sheets were much larger, it was possible to make the measurements using a more accurate, automated device (Thompson et al., 1993). Subtle variations in texture were sensed in agreement with independent measurements using $\mathrm{X}$-ray and neutron diffraction.

In section II we present the theory underlying the ultrasonic characterization of texture. Section III describes the samples in greater detail and section IV describes the experimental techniques, which include two ultrasonic approaches (for the small and large samples), X-ray diffraction and neutron diffraction. The data obtained on the first set of sheets was not ideal because of their smaller size, and some new regression procedures were required to accurately extract the texture information, as presented in section V. The texture information inferred from the ultrasonic measurements is discussed and compared to the X-ray and neutron scattering results in section VI. The paper concludes with a summary in section VII. 


\section{THEORY}

\section{Description of Texture}

Polycrystals exhibit anisotropic macroscopic properties when (a) the individual crystallites are anisotropic and (b) they have a preferred orientation (texture). The latter is typically sensed by diffraction methods and is quantified through the use of an orientation distribution function (ODF). The ODF is the three-dimensional representation of the distribution of orientations quantified by a probability density as a function of three Euler angles describing the crystallite orientation with respect to the sample axis. Typically, the ODF is plotted as rectangular sections of a three-dimensional Euler-angle space. Each section contains contours showing relative densities at each point. Roe (1965) and Bunge (1982) concurrently developed this 3-D, quantitative representation of texture using slightly different conventions. The experimental determination of the ODF involves combining the information in several pole figures to obtain one ODF representing the texture of the sample. This is a useful but time-consuming technique which has recently been improved upon due to the ever increasing speed of modern computers; however, this scheme still requires the measurement of a number of pole figures. Once the ODF is determined, it can be used to predict material properties, such as elastic and plastic properties.

The ODF can be represented by an expansion in generalized spherical harmonics. The coefficients of this expansion are called the orientation distribution coefficients (ODCs) and are the quantities related to material properties. Throughout this paper the author will be using Bunge's notation. The ODCs inherently depend on both the sample and crystal symmetries. The ODF, $f\left(\phi_{1}, \Phi, \phi_{2}\right)$, can be given by the following equation,

$$
\begin{aligned}
& \mathrm{f}\left(\phi_{1}, \Phi, \phi_{2}\right)=\sum_{l=0}^{\infty} \sum_{\mu=-l}^{M(l)} \sum_{v=-l}^{N(l)} C_{t}^{\mu v} T_{l}^{\mu v} \\
& \text { where, } \\
& T_{t}^{\mu \nu}=e^{-i \mu \phi_{2}} P_{t}^{\mu v}(\cos (\Phi)) e^{-i \nu \phi_{1}}
\end{aligned}
$$

The $\mathrm{C}^{\mu v}$ are the ODCs, $\mathrm{P}^{\mu v}$ are generalizations of the associated Legendre functions; $\mathrm{M}(l)$ and $\mathrm{N}(l)$ represent the number of linearly independent ways the symmetry (crystal and sample, respectively) can be fulfilled, and $\phi_{1}, \Phi$, and $\phi_{2}$ are Euler angles. The sample symmetry and the crystallite symmetry determine which ODCs will be present.

\section{Ultrasonic Determination of ODCs}

Several authors have realized that, since elastic properties could be predicted by the ODF, measurement of elastic properties should provide information on the texture. This turns out to be true but only to a limited extent. Since elasticity is a fourth ranked tensor quantity, only ODCs of fourth order or less can be predicted (Sayers, 1982). The basic scheme is to measure the anisotropy of the ultrasonic wave speed. This relates to the anisotropy of the elastic moduli which then predicts the ODCs. Equations relating the ODCs to the speeds of symmetric Lamb waves in plates or sheets are given in equation (2) (Thompson et al., 1989), where $\rho$ is the density, $\mathrm{V}_{\mathrm{So}}\left(\Theta=0^{\circ}, 45^{\circ}, 90^{\circ}\right)$ is the velocity of the fundamental symmetric Lamb wave in the indicated direction. $\mathrm{P}$ and $\mathrm{L}$ are polycrystalline averages of the single crystal elastic constants corresponding 
to the Lame elastic constants $\lambda$ and $\lambda+2 \mu$, respectively. $\mathrm{C}$ is a measure of the single crystal anisotropy $\left(C_{11}-C_{12}-2 C_{44}\right)$. The type of wave used is not crucial as any elastic wave will provide information about elastic properties; however, the formulae used will differ in detail.

$$
\begin{aligned}
C_{4}^{13} & =\frac{3 \sqrt{15} \rho}{2 C}\left[V_{S o}^{2}\left(0^{\circ}\right)+V_{S o}^{2}\left(90^{\circ}\right)-2 V_{S o}^{2}\left(45^{\circ}\right)\right] \\
C_{4}{ }^{12} & =\frac{3 \sqrt{105} \rho}{2\left(1+\frac{2 P}{L}\right) C}\left[V_{S o}^{2}\left(90^{\circ}\right)-V_{S o}^{2}\left(0^{\circ}\right)\right] \\
C_{4}^{11} & =\frac{15 \sqrt{21} \rho}{2\left[3+8\left(\frac{P}{L}\right)+8\left(\frac{P}{L}\right)^{2}\right] C}\left[V_{S o}^{2}\left(0^{\circ}\right)+V_{S o}^{2}\left(90^{\circ}\right)+2 V_{S o}^{2}\left(45^{\circ}\right)-\frac{4}{\rho}\left(\mathrm{L}-\frac{P^{2}}{L}\right)\right]
\end{aligned}
$$

It is important to note that $\mathrm{C}_{4}{ }^{12}$ and $\mathrm{C}_{4}{ }^{13}$ can be inferred from relative velocity measurements, whereas $\mathrm{C}_{4}{ }^{11}$ depends on the difference of an average absolute measurement and theoretical expectations for an isotropic polycrystalline aggregate. Thus $\mathrm{C}_{4}{ }^{11}$ is influenced by the greater uncertainties in absolute velocity measurements as compared to relative velocity measurements as well as uncertainties in the effects of alloying elements on the isotropic moduli, $\mathrm{L}$ and $\mathrm{P}$.

\section{Diffraction Determination of $O D C s$}

The theory required to obtain ODCs from diffraction data is well-developed, and has been fully described previously (Roe, 1965; Bunge, 1982). The intensity of a diffraction peak is directly proportional to the volume fraction of grains, within the measurement volume, whose (hkl) plane-normals are parallel to the bisector of the incident and diffracted beams. A specimen is oriented systematically to sweep this bisector through all possible directions in the specimen. The diffraction peak intensity, $\mathrm{P}$, is measured as a function of direction, specified as a vector, $y$, with reference to specimen-fixed axes. Maps of $\mathrm{P}_{\mathrm{h}}(\mathrm{y})$ are called pole figures and are measured for each of a selection of crystallographic directions, specified by a vector, $h$. The collection of pole figures can be represented by a series expansion of spherical harmonics, with the expansion coefficients being the ODCs we seek:

$$
P_{h}(y)=\sum_{l=0}^{\infty} \sum_{v=1}^{N(l)}\left[\frac{4 \pi}{2 l+1} \sum_{\mu=1}^{M(l)} C_{l}^{\mu v} k_{l}^{* * \mu}(h)\right] k_{l}^{* v}(y)
$$

Here the functions $k_{l}^{* * \mu}(\mathrm{h})$ and $k_{l}^{v}(\mathrm{y})$ contain the effects of crystallographic and specimen symmetry, respectively. When a complete set of pole figure data is available, the ODCs can be obtained by a least squares analysis, with more complex procedures employed otherwise.

$\mathrm{X}$-ray and neutron diffraction provide the raw pole figure data for the determination of ODCs. The advantages of neutron diffraction for measurements of the volumetric average texture in a bulk specimen, and various neutron techniques have been described previously (Bunge, 1989). X-ray diffraction is, by far the most accessible, and widelyused technique for texture analysis. However, as already explained, when used in a nondestructive mode, it is most sensitive to a thin layer of material near the measurement surface. 


\section{SAMPLES}

Experiments were conducted on two sets of samples, each consisting of AA3004 can stock which had undergone hot rolling. Experiments on the first set of samples were intended to determine whether the ultrasonic technique could differentiate rolling and recrystallization textures. They were cut from 3 sheets, having respective thicknesses of $2.654 \mathrm{~mm}$ (sheet 1), $2.652 \mathrm{~mm}$ (sheet 2) and $2.570 \mathrm{~mm}$ (sheet 3). Sheets 1 and 3 were in the form of rectangles, with long dimensions on the order of $250 \mathrm{~mm}$ and small dimensions on the order of $125 \mathrm{~mm}$. Sheet 2 was somewhat smaller than the others, which posed some difficulty in the velocity measurement. Sheet 2 had been processed through a hot mill and was in an unrecrystallized state. The other two samples (sheets 1 and 3) were at the same stage of processing and were in a fully recrystallized condition, showing a predominantly cube texture. Chemical composition differences led to a stronger cube texture in sheet 3 as compared to sheet 1 . Experiments on the second set of sheets were designed to evaluate whether the ultrasonic technique was sensitive to more subtle variations in texture. These were all in the fully recrystallized condition, but contained different amounts of cube texture, with sheet 4 having the weakest value, sheet 5 an intermediate value and sheet 6 the strongest value. In addition, there were differences from the center to the edge of each sheet. These samples had much larger lateral dimensions, being in excess of $600 \mathrm{~mm} \times 600 \mathrm{~mm}$.

\section{EXPERIMENTAL APPROACH AND OBSERVATIONS}

Two distinct techniques were used for the ultrasonic measurements. On the second set of larger samples, a fully automated instrument was available for use (Thompson et al., 1993). However, the samples studied initially were too small for use with that instrument, so a second technique had to be employed. In that case, we adopted a modification of a technique previously used by Clark Jr. et al. (1987; 1993).

\section{Manual Ultrasonic Measurements on Small Sheets}

The classical approach to measuring velocity involves plotting the arrival time of a particular waveform feature as a function of propagation distance. Here, we utilized $S_{o}$ Lamb modes of plates (Auld; 1973), excited and detected at a frequency of 448 $\mathrm{kHz}$ by electromagnetic-acoustic transducers (EMATs) (Thompson, 1990). Unfortunately, the spatial length of our EMATs, coupled with a minimum separation required to allow the high gain electronic receivers to recover from the electrical break-through pulse, made it impractical to gather data at a large number of separations for waves travelling in the smaller dimensions of our samples. Hence we modified a procedure originally employed by Clark.

Clark was interested in predicting steel sheet formability based on the angular dependence of the ultrasonic velocity. His strategy was to infer the velocity from the delay of a particular zero crossing of a signal which had propagated between a pair of EMATs, separated by a fixed separation (Clark Jr. et al., 1987; Clark Jr. et al., 1993). To determine the exact path length that should be used to obtain the correct absolute velocity, a calibration experiment was required. This involved measuring an absolute velocity on one sheet. This absolute velocity was then used to determine an effective distance between the transmitting and receiving transducers at the fixed 
separation, the distance being chosen equal to the product of the measured absolute velocity and the time of the observed zero-crossing. Once this effective distance was known, the angular dependence of the velocity was inferred from the angular dependence of the time of the zero-crossing. Clark checked his procedure by making absolute measurements in three directions on a sheet $\left(\theta=0^{\circ}, 45^{\circ}, 90^{\circ}\right.$ with respect to the rolling direction), using one of these as a calibration, and comparing the other two absolute velocities to the velocities inferred from the zero-crossing times and effective distance determined by the above procedure. The results agreed to within parts in $10^{4}$.

In our work, absolute velocity measurements were made along the longest direction of each of the three sheets in the first set of samples by selecting a particular zerocrossing in the received burst and plotting its time of arrival versus the EMAT separation. This separation was varied by inserting aluminum spacers of known lengths, ranging from 10 to $20 \mathrm{~cm}$, between the EMATs. The time was measured with a time averaging counter. The slope of the plot of separations versus time determined the absolute velocity.

In principle, the accuracy of this procedure can be determined from that of the time and distance measurements (Johnson and Thompson, 1993). Each measurement of time was based on the average of 1000 successive waveforms, performed automatically by the counter. The standard deviation of this population was typically $11 \mathrm{~ns}$, implying that the standard deviation of the estimate of the mean was $(11 \mathrm{~ns}) / \sqrt{1000} \sim 0.3 \mathrm{~ns}$. The spacers had lengths known to $\pm 0.0127 \mathrm{~mm}\left( \pm 0.5 \times 10^{-3}\right.$ inches $)$. Based on these values, the uncertainty in the velocity, estimated from 11 pairs of separation and time data taken over separations ranging from 10 to $20 \mathrm{~cm}$ should in principle (Johnson and Thompson, 1993) be $\pm 6 \times 10^{-4} \mathrm{~mm} / \mu \mathrm{s}$, about $0.01 \%$. This in principle accuracy is limited by the uncertainty in the spacer length rather than the time measurement.

When standard regression analysis techniques were applied to the data, the results in Table 1 were obtained. The observed standard deviations were about an order of magnitude greater than those expected in principle. We do not have a detailed understanding of the reason, but recognize some contributing factors such as plate curvature, EMAT lift-off effects (Clark Jr. et al., 1987), and lack of perfect contact between EMATs and spacers. Nevertheless, the accuracy of $0.1 \%$ is sufficient to obtain the desired information, as will be seen below.

As noted above, the small dimensions of the samples precluded the application of this procedure for other directions. Hence, motivated by the previously discussed work of Clark et al, the transducers were fixed at an unknown distance, $\mathrm{d}_{\mathrm{i}}$, and the time delay to a particular zero-crossing was measured at $0^{\circ}, 45^{\circ}, 90^{\circ}$ to the rolling direction for each sheet. Figure 2 schematically illustrates this procedure. The above steps were repeated for four $d_{i}$ 's. The raw times are given in Table 2. These were also measured with a time averaging counter. In some cases, there was a little more noise than in

Table 1 Absolute Velocities on First Set of Sheets.

\begin{tabular}{lccc}
\hline Sheet & Direction & $\begin{array}{c}\text { Velocity } \\
(\mathrm{mm} / \mu \mathrm{s})\end{array}$ & $\begin{array}{c}\text { Standard Deviation } \\
(\mathrm{mm} / \mu \mathrm{s})\end{array}$ \\
\hline 1 & TD & 5.360 & 0.009 \\
2 & TD & 5.418 & 0.005 \\
3 & RD & 5.274 & 0.005 \\
\hline
\end{tabular}




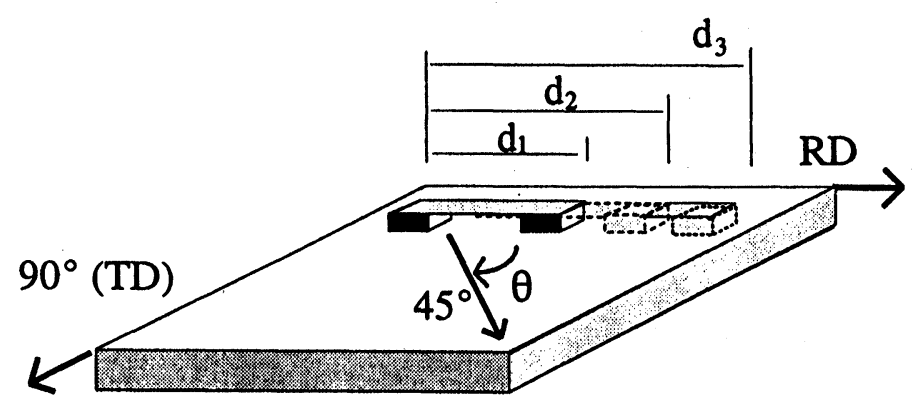

Figure 2 Representation of measurement scheme.

the absolute measurements, but based on the statistical estimates, the precision in the determination of time was at least $1 \mathrm{~ns}$. We have only quoted times to an accuracy of $10 \mathrm{~ns}$ in Table 2, based on our experience of greater errors in absolute measurements than would be expected in principle based on the accuracies of individual time and distance measurements.

Further processing of this raw data to obtain velocities and texture parameters will be discussed in the following sections. However, it is clear from the raw data that the rolling texture of sheet 2 is clearly differentiated from the recrystallization textures of sheets 1 and 3 , since $t\left(45^{\circ}\right)>t\left(0^{\circ}\right)$ and $t\left(45^{\circ}\right)>t\left(90^{\circ}\right)$ in sheet 2 while $t\left(45^{\circ}\right)<$ $\mathrm{t}\left(0^{\circ}\right)$ and $\mathrm{t}\left(45^{\circ}\right)<\mathrm{t}\left(90^{\circ}\right)$ in sheets 1 and 3 .

\section{Automated Measurements on Large Sheets}

Measurements on the second set of sheets were made using an automated texture measurement instrument called Ultraform (Thompson et al., 1993). Ultraform uses the same basic technique as the hand measurements with some modifications. $S_{0}$ Lamb waves are again excited and detected by EMATs at a frequency of approximately $\mathbf{5 5 0}$ $\mathrm{kHz}$. The instrument uses two transmitters and one receiver in each of the three directions needed, $0^{\circ}, 45^{\circ}, 90^{\circ}$. For a given direction, a triggered wave is transmitted simultaneously from both transmitters. It is detected as a pair of signals at the receiver. These waveforms are digitized and then processed in the frequency domain to determine the wave velocities. The central feature is a plot of the relative phase of the two received

Table 2 Zero-crossing delays in $\mu$ s.

\begin{tabular}{lccccccccc}
\hline & \multicolumn{3}{c}{ Sheet 1 (recrystallized) } & \multicolumn{3}{c}{ Sheet 2 (rolled) } & \multicolumn{3}{c}{ Sheet 3 (recrystallized) } \\
$d_{i}$ & $t\left(0^{\circ}\right)$ & $t\left(45^{\circ}\right)$ & $t\left(90^{\circ}\right)$ & $t\left(0^{\circ}\right)$ & $t\left(45^{\circ}\right)$ & $t\left(90^{\circ}\right)$ & $t\left(0^{\circ}\right)$ & $t\left(45^{\circ}\right)$ & $t\left(90^{\circ}\right)$ \\
\hline$\# 1$ & 30.32 & 30.21 & 30.22 & 29.66 & 29.99 & 29.94 & 30.56 & 30.31 & 30.43 \\
$\# 2$ & 32.21 & 32.09 & 32.09 & 31.53 & 31.83 & 31.75 & 32.39 & 32.20 & 32.29 \\
$\# 3$ & 34.04 & 33.90 & 34.04 & 33.22 & 33.59 & 33.53 & 34.28 & 34.10 & 34.19 \\
$\# 4$ & 35.92 & 35.78 & 35.80 & 35.20 & 35.50 & 35.41 & 36.20 & 35.92 & 36.07 \\
\hline
\end{tabular}


waveforms versus frequency, the slope of which is simply related to velocity after correction for a slight geometrical dispersion associated with the finite ratio of plate thickness to wavelength. Laboratory evaluation of Ultraform indicates absolute accuracies in velocity of $10^{-3}$ and relative accuracies of $10^{-4}$ (Thompson et al., 1993). Ultraform then calculates the ODCs from these velocities using equation (2) above.

\section{$X$-ray diffraction}

The texture was independently characterized on each set of sheets using X-ray diffraction (Mo X-rays), performed on the mid-plane of the sheet. Four incomplete pole figures, (200), (111), (220) and (113), were obtained in each case, from which orientation distribution functions were computed. In the second set of sheets, in which transverse variations in texture were of interest, the texture was characterized at both the sheet center and edge.

\section{Neutron diffraction}

On sheets 2 and 3, neutron diffraction characterization of the texture was also performed, motivated by the desire to gain further information in a few cases where there were significant differences between the ultrasonic and X-ray predictions. Neutron measurements were considered more appropriate than the mid-plane X-ray measurements for comparing to the ultrasonic results since both the neutron and ultrasonic techniques provide through thickness averages while the mid-plane $\mathrm{X}$-ray measurements, in the reflection mode utlized, sense only a thin surface layer.

Neutron diffraction measurements were performed in Canada at Chalk River Laboratories, a part of Atomic Energy of Canada Limited, with the E3 neutron diffractometer at the NRU reactor.

The specimen was mounted on an Eulerian cradle, which was programmed to orient the material systematically, sweeping the bisector of the incident and diffracted beams through a complete hemisphere of specimen directions. Complete pole figures were obtained for the (111), (200) and (220) diffraction peaks from the aluminium alloy. A background pole figure was also measured by placing the neutron detector at a scattering angle free of diffraction peaks and performing the usual orientational scan. The incident and diffracted beams were collimated by Soller slits to have angular divergences of about $0.5^{\circ}$ in the scattering plane. The cross sections of these beams were large, $50 \mathrm{~mm} \times 50 \mathrm{~mm}$, so regardless of orientation, the complete specimen volume was always fully bathed in the neutron beam. As a result of these experimental arrangements, there were no significant geometrical corrections to make to the pole figures prior to the analysis that yielded the ODCs.

\section{PROCESSING THE MANUAL ULTRASONIC DATA}

The raw data obtained on each of the three initial samples was an absolute velocity in one direction (Table 1) and a matrix of 12 times of arrival (3 directions $\times 4$ transducer separations) of a selected zero-crossing of the received toneburst (see Table 2). As noted previously, the velocities were initially inferred based on a technique applied by Clark Jr. et al $(1987 ; 1993)$ to steel sheet, which involved assigning an effective propagation distance to each fixed transducer separation. 
A triggered waveform can be thought of as a pulse starting at zero time (see Figure 3). Because of the finite length of the EMAT transducers, and the fact that they are excited by a toneburst, a particular feature in a received signal is delayed from the trigger pulse by more than the transducer separation divided by the wavespeed. In Clark's method, the determination of the transducer separation ignored this fixed delay associated with the tone burst width. In applying his technique to our set of sheets, we had the option of determining the effective distance on one sheet and using it to interpret all

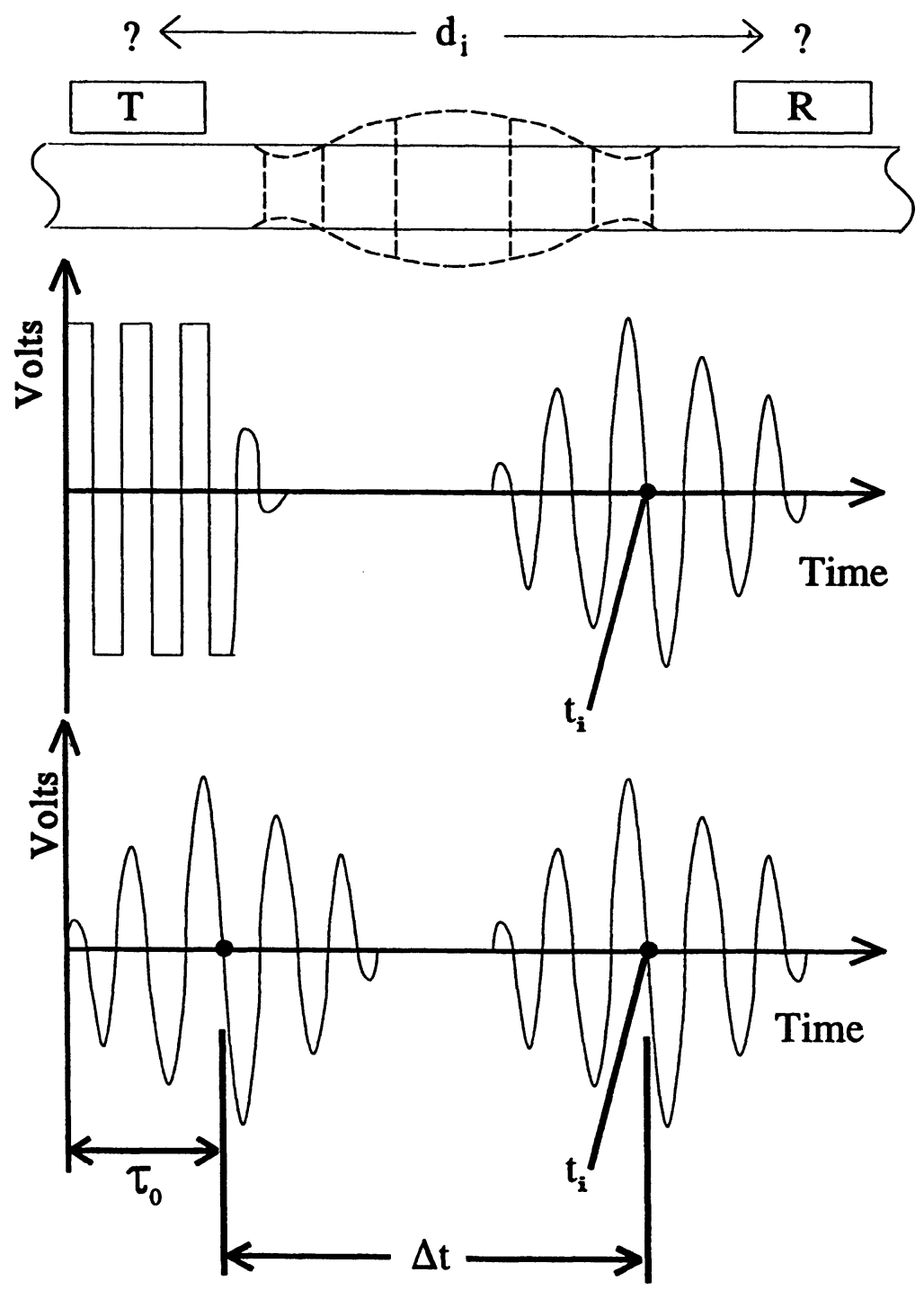

Figure 3 Schematic of waves generated during measurements. 
data (as was done by Clark in studying a large set of steel sheets) or determining it on each sample, as is possible in our study given the data in Table 1. Choosing the latter approach, and averaging the velocities obtained at the four separations for each angle, we obtained the velocities shown in the first row of Table 3.

In examining the data, however, we noticed that the effective separation, $d$, depended systematically on the sheet, being essentially equal in sheets 1 and 2 but systematically smaller by about $0.6 \%$ in sheet 3 . Since the transducers were rigidly held at the same distance on all sheets, this raised a concern. It was initially speculated that, since the plates had slightly different thicknesses, the effect was associated with geometrical dispersion (a slight dependence of guided wave speed on the plate thickness). However, theoretical analysis did not support this analysis. It was then observed that the changes in effective distance appeared to be related to the absolute velocity in the calibration direction, as given in Table 1. This led to the following interpretation and modified data processing procedure.

Consider the bottom sketch in Figure 3, which schematically shows that the observed time of the selected zero-crossing can be considered to be composed of a fixed delay time, $\tau_{\mathrm{o}}$, associated with the finite temporal length of the excitation pulse and the spatial length of the EMATs, and the propagating delay, $\Delta \mathrm{t}$. To account for these effects, we define a modified effective distance

$$
D_{i}=\left[t_{i j}\left(\Theta_{\mathrm{o}}\right)-\tau_{\mathrm{o}}\right] \cdot V_{j}\left(\Theta_{\mathrm{o}}\right)
$$

using equation (4). This equation uses $i$ as the separation counter, and $j$ as the sheet counter. The $t_{\mathrm{ij}}\left(\theta_{\mathrm{o}}\right)$ are the known measured times for waves propagating in the calibration direction, $\tau_{\mathrm{o}}$ is the unknown fixed delay and $\mathrm{V}_{\mathrm{j}}\left(\theta_{\mathrm{o}}\right)$ is the known absolute velocity in a particular direction on sheet $j$. For our set of data, there are twelve independent forms of equation (4), where $i$ ranges over 4 separations and $j$ ranges over three sheets. These are solved, in a least squares sense, for the value of $\tau_{\mathrm{o}}$ and the four $D_{i}$. Given these values, the velocities in the other directions are determined from the inverse of the slope of a regression line passing through these four points on the $t_{i j}(\theta)$ versus $D_{i}$ plot and forced through a y-intercept of $\tau_{\mathrm{o}}$. We found that this procedure fit the data considerably better than when $\tau_{\mathrm{o}}$ was taken to be zero, equivalent to Clark's procedure.

The resulting velocities are presented in the second row of Table 3. Although the shifts were small, ranging from $0.1 \%$ to $0.4 \%$, they were considered to be significant in terms of the high precision desired.

Table 3 Ultrasonic Velocities on First Set of Samples (in $\mathrm{cm} / \mu \mathrm{s}$ ).

\begin{tabular}{lccccccccc}
\hline & $0^{\circ}$ & $\begin{array}{c}\text { Sheet } 1 \\
45^{\circ}\end{array}$ & $90^{\circ}$ & $0^{\circ}$ & $45^{\circ}$ & $\begin{array}{c}\text { Sheet } 2 \\
90^{\circ}\end{array}$ & $0^{\circ}$ & $\begin{array}{c}\text { Sheet } 3 \\
45^{\circ}\end{array}$ & $90^{\circ}$ \\
\hline $\begin{array}{l}\text { Clark's } \\
\text { Approach }\end{array}$ & 0.5499 & 0.5520 & 0.5512 & 0.5615 & 0.5559 & 0.5572 & 0.5412 & 0.5449 & 0.5430 \\
$\begin{array}{l}\text { Modified } \\
\text { Approach }\end{array}$ & 0.5480 & 0.5507 & 0.5497 & 0.5638 & 0.5565 & 0.5581 & 0.5418 & 0.5466 & 0.5441 \\
\hline
\end{tabular}


Examination of the raw time data indicates several interesting points. First, the shifts in time between the sheets and directions is quite small, being on the order of tenths of microseconds. Nevertheless, with modern electronics, such shifts can be easily measured. This is confirmed by noting that the zero-crossing delays order in a fashion consistent with the absolute velocities for the directions and materials where those were determined. Second, it is clear that $V^{2}>V^{1}>V^{3},\left[v^{1,3}(0)-v^{1,3}(90)\right]<0,\left[v^{2}(0)-\right.$ $\left.v^{2}(90)\right]>0, v^{1,3}(45)>\left[v^{1,3}(0)+v^{1,3}(90)\right] / 2, v^{2}(45)<\left[v^{2}(0)+v^{2}(90)\right] / 2$, where $V=$ $[v(0)+v(90)+2 v(45)] / 4$ and the superscripts define sheets, not exponents. Equation (2) then implies that $\mathrm{C}_{4}{ }^{11}(2)<\mathrm{C}_{4}{ }^{11}(1)<\mathrm{C}_{4}{ }^{11}(3), \mathrm{C}_{4}{ }^{12}(2)>0, \mathrm{C}_{4}{ }^{12}(1,3)<0, \mathrm{C}_{4}{ }^{13}(2)$ $<0, \mathrm{C}_{4}{ }^{13}(1,3)>0$ where the argument here denotes the sheet number. We thus again see that there is a clear differentiation between the rolled (sheet 2 ) and recrystallized (sheets 1 and 3) samples.

Figure 4 presents the predicted angular form of the velocities, obtained by fitting the function $\mathrm{A}+\mathrm{B} \cos (2 \theta)+\mathrm{C}(1-\cos (4 \theta))$ to the data at $\theta=0^{\circ}, 45^{\circ}, 90^{\circ}$. The aforementioned distinctions between the three sheets are clearly evident.

It should be noted that the simpler procedure of Clark was quite adequate for his needs. Differences between the conditions encountered in our work and his work are the much greater propagation distances in his experiments, making $\tau_{\mathrm{o}}$ a smaller fraction of the observed times, the much greater elastic anisotropy of steel, making the required precision in velocity determination less stringent, and the fact that Clark's final output was to be empirically correlated with plastic strain ratios in steel whereas we wish to make direct comparisons to values of $\mathrm{C}_{4}{ }^{\mu v}$ determined by X-ray or neutron diffraction.

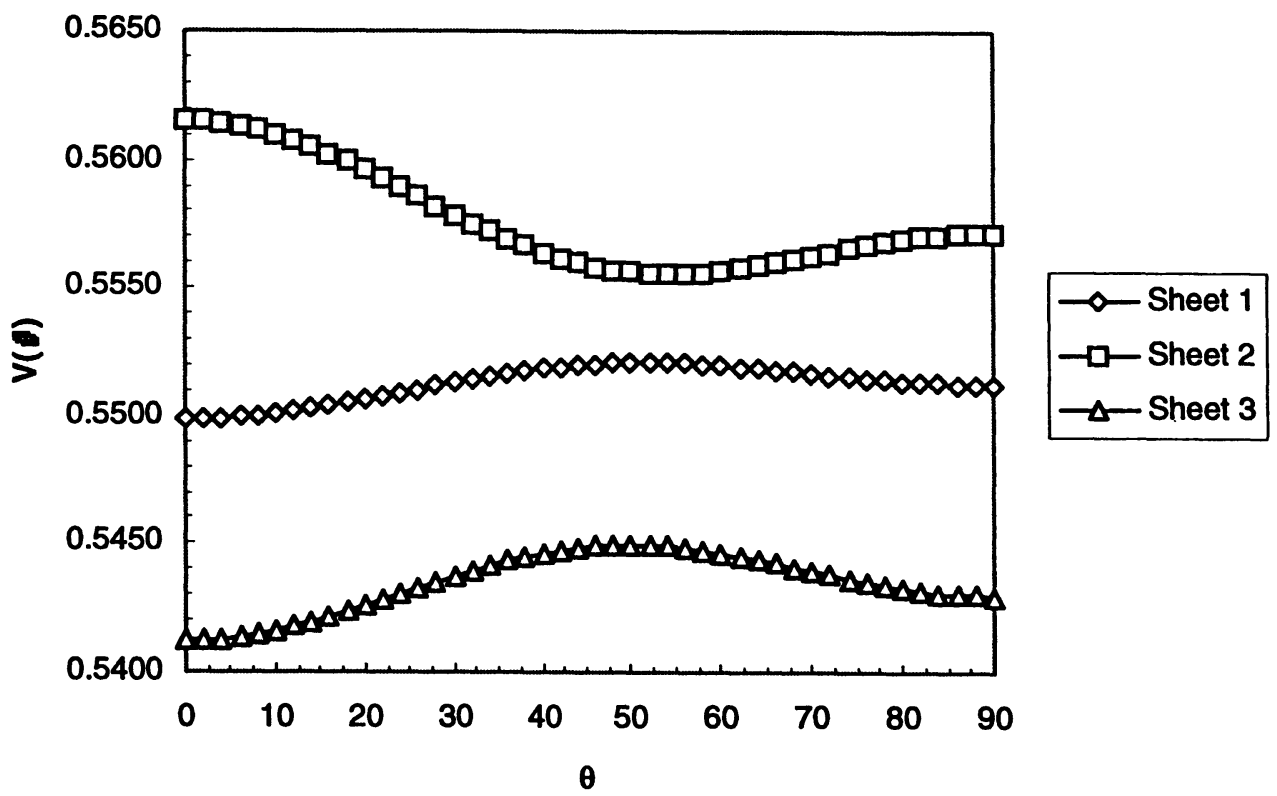

Figure 4 Angular variation of ultrasonic velocity in the plane of the sheet. Values at $0^{\circ}, 45^{\circ}$, and $90^{\circ}$ are the measured ultrasonic velocities and the remainder of the curve is plotted based on the expected theoretical variation of $A+B \cos (2 \theta)+C(1-\cos (4 \theta))$. 


\section{QUANTITATIVE CHARACTERIZATION OF TEXTURE}

\section{Differentiation of Rolling and Recrystallization Textures}

Having convinced ourselves that the data passes all qualitative tests, we calculate the ODCs using equation (2) above based on the velocities inferred from the raw data by the two methods discussed above. The results of these calculations along with neutron diffraction data for Sheets $2 \& 3$ are plotted in Figure 5 versus the $\mathrm{X}$-ray diffraction data. Results for $\mathrm{C}_{4}{ }^{11}$ are not included in this figure, but will be discussed in a later section. The ultrasonically determined values of $\mathrm{C}_{4}{ }^{12}$ and $\mathrm{C}_{4}{ }^{13}$ for Sheets 1 \& 3 compare very favorably with the $\mathrm{X}$-ray and Neutron diffraction values which suggests that recrystallization textures are easily measured using ultrasonics. It should also be noted that, in each case, the new signal processing produced results that were closer to both

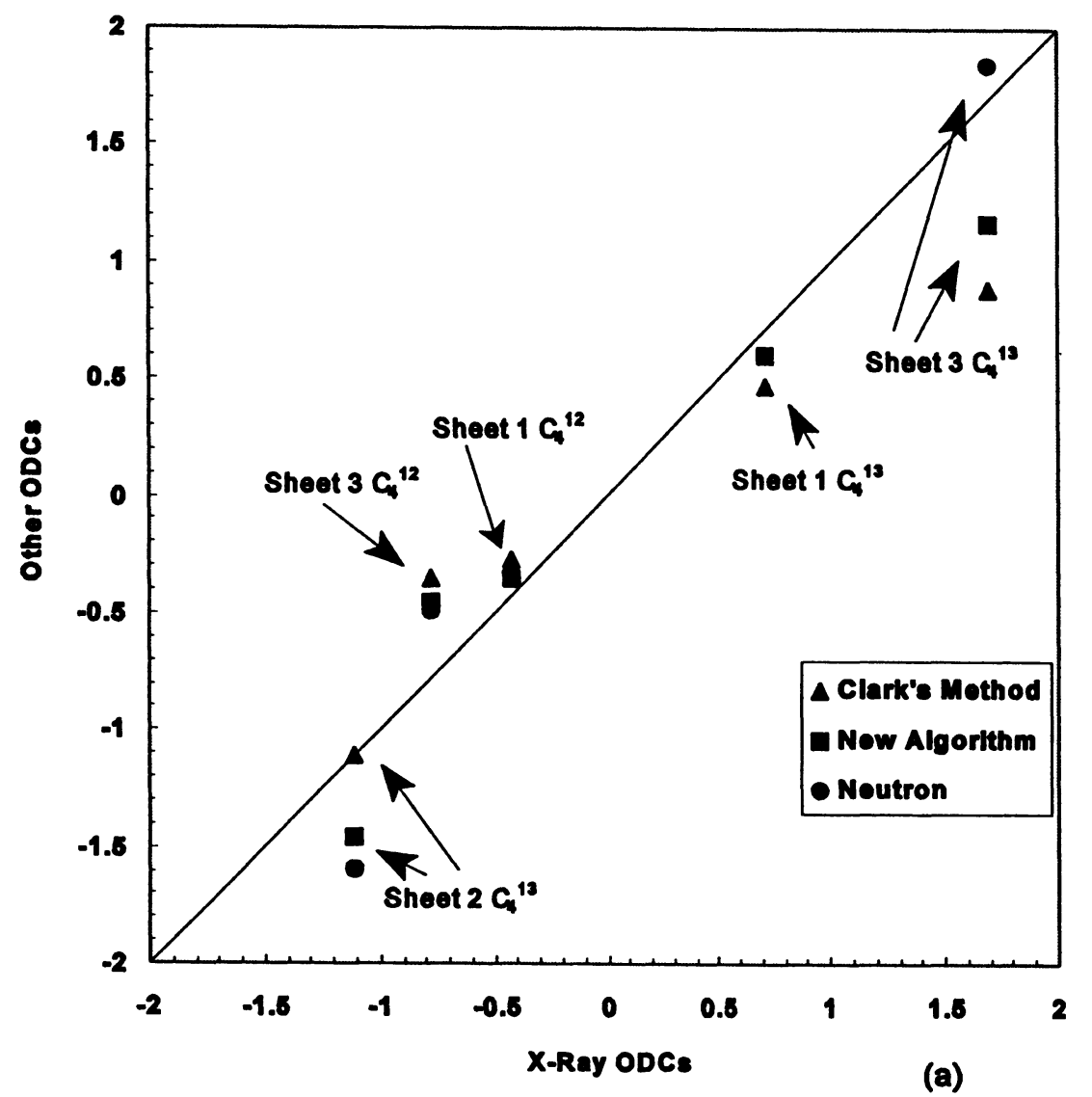

Figure 5 Comparison of ODCs predicted by two slightly different ultrasonic methods and neutron diffraction to X-ray diffraction. No neutron measurements were made on sheet 1 and $\mathrm{C}_{4}{ }^{12}$ is not shown for sheet 2 as discussed in the text. 
the X-ray and neutron diffraction data than did Clark's method. The data for sheet 2 does not support as simple an interpretation. For $\mathrm{C}_{4}{ }^{13}$, we notice that the predictions of the modified ultrasonic technique are farther from the $\mathrm{X}$-ray measurements than are those based on Clark's method. We note, however, that the modified method leads to predictions that are closer to the neutron measurements. It is well known that the rolling texture has gradients through the thickness (Ren, 1996), leading to differences between the mid-plane $\mathrm{X}$-ray and neutron values for $\mathrm{C}_{4}{ }^{13}$. The fact that the modified ultrasonic prediction is closer to the neutron measurements is consistent with the fact that both measure volumetric averages.

The situation with $\mathrm{C}_{4}{ }^{12}$ in sheet 2 is more complex, as both ultrasonic methods yield predictions of comparable magnitude, but opposite sign, to the predictions of either diffraction method. We do not have a definitive interpretation of this result. We note, however, that this sample was smaller than desired and energy reflected from the edges could have interfered with the measurement. It is also possible that there was a mislabelling of the sample axes when the ultrasonic data were taken because an interchange of the RD and TD would account for the difference. Other microstructural features could be playing a role, for example, precipitates or dislocations will also affect the measured velocity. However, since no such sign discrepancies have been reported on the large number of aluminum samples that have been studied previously (Clark Jr. et al., 1988; Reno, Fields, Clark Jr., 1988; Cassier, Donadille, Bacroix, 1989; Borsutski et al., 1993; Thompson et al., 1993), we expect that the experimental difficulties is the likely cause. Unfortunately, we cannot remeasure the ultrasonic velocities because the samples have been subsequently destroyed. Because of these complications, which we believe to be unique to this particular experiment, the results for $\mathrm{C}_{4}{ }^{12}$ on sheet 2 are not presented in Figure 5 .

Table 4 presents the numerical values of the ultrasonic (new algorithm) and X-ray determinations of the ODCs. In addition to $\mathrm{C}_{4}{ }^{12}$ and $\mathrm{C}_{4}{ }^{13}$ that were presented graphically, $\mathrm{C}_{4}{ }^{11}$ is included. The obvious discrepancies between the ultrasonic and $\mathrm{X}$-ray values will be discussed in section VI C.

\section{Subtle Variations in Recrystallization}

The second set of sheets were recrystallized to varying degrees. Measurements were made to determine how easily ultrasonics could distinguish between degrees of recrystallization. In addition to variation between the sheets, each sheet contained a variation in the texture along the width from the center to the edge of the rolled sheet.

Measurements were taken at two inch intervals across each sheet using Ultraform. The ultrasonic results are plotted in Figure 6 along with X-ray diffraction results. The $\mathrm{X}$-ray results were taken at the center and edge only. One can easily see that the ultrasonic measurements for $\mathrm{C}_{4}{ }^{12}$ and $\mathrm{C}_{4}{ }^{13}$ have the same magnitude and vary in the same sense across the sheet as the $\mathrm{X}$-ray predictions. $\mathrm{C}_{4}{ }^{11}$ values also show the same trends across the sheet, but differ in magnitude. This difference will be discussed in greater detail in the next subsection.

\section{Offset in $C_{4}{ }^{11}$}

Predictions of $\mathrm{C}_{4}{ }^{11}$ for every sheet seemed to have a significant negative offset with respect to the $\mathrm{X}$-ray and neutron diffraction results. To explain this offset in the prediction of $\mathrm{C}_{4}{ }^{11}$, one must look into the calculation of this ODC. Equation (2) shows the relation between $\mathrm{C}_{4}{ }^{11}$ and the measured velocities, as well as that for the other 
Table 4 Comparison of ultrasonic, X-ray, neutron and ideal ODCs for the all samples. Results for sheet 1,2 and 3 are computed using the modified method discussed above.

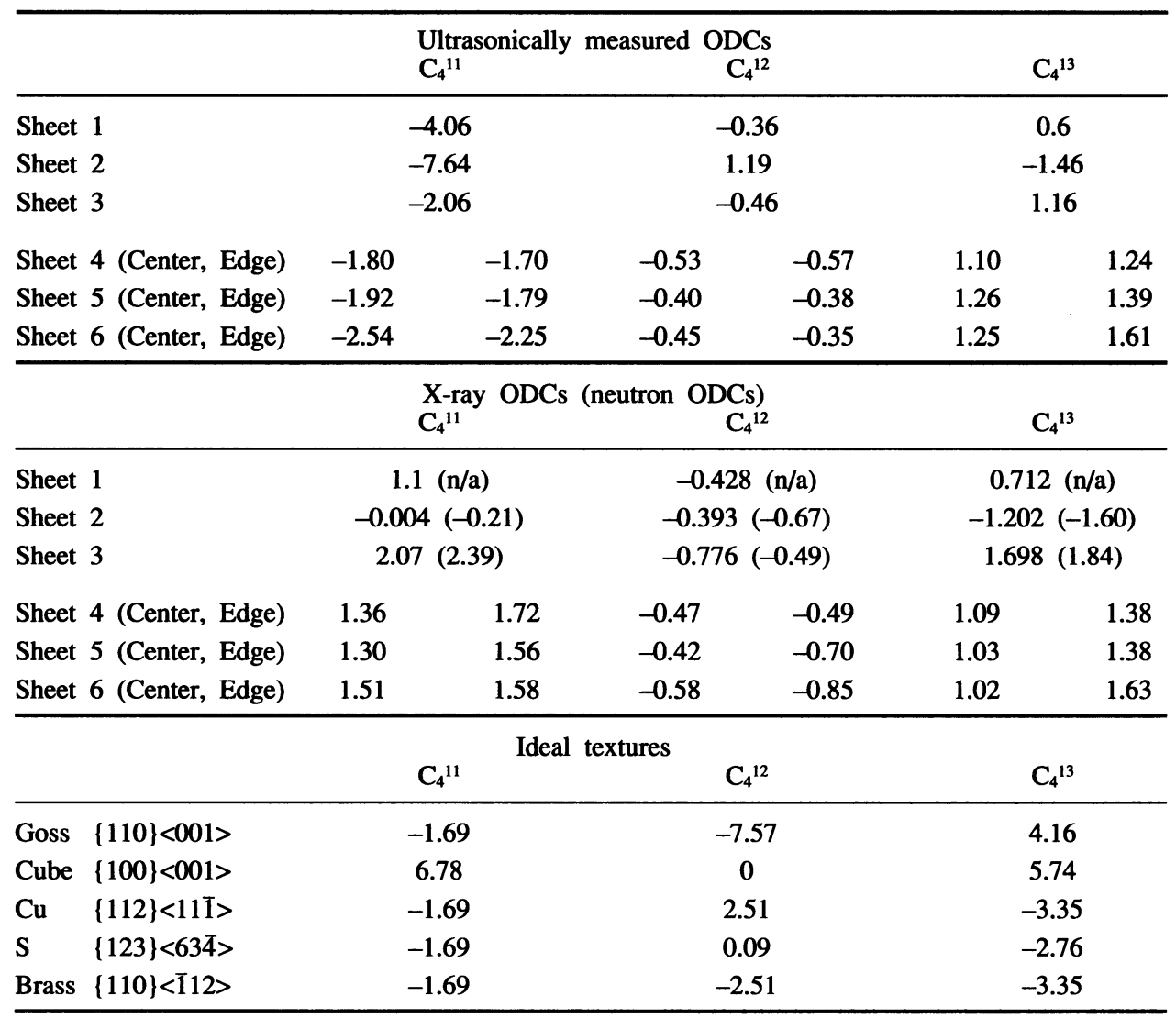

ODCs. There are two important differences between the calculation of $\mathrm{C}_{4}{ }^{11}$ and that for $\mathrm{C}_{4}{ }^{12}$ and $\mathrm{C}_{4}{ }^{13}$. First, $\mathrm{C}_{4}{ }^{11}$ depends on absolute, rather than relative velocity measurements. Second, the average of the absolutely measured velocities must be compared to the value that would be observed in the absence of texture, whose square is described by the last term in the square brackets, $(4 / \rho)^{*}\left(\mathrm{~L}-\mathrm{P}^{2} / \mathrm{L}\right)$. This term would be expected to depend on alloying. In the absence of knowledge of the alloying effect, the isotropic value for pure aluminum has been used in our calculation, based on the single crystal elastic constants (SCECs) and use of the Hill averaging procedure to obtain $\mathrm{L}$ and $\mathrm{P}$. While $\mathrm{C}_{4}{ }^{12}$ and $\mathrm{C}_{4}{ }^{13}$ also depend on the SCECs through $\mathrm{L}$ and $\mathrm{P}$, the dependence is in a multiplicative factor instead of a subtractive term. Propagation of any error associated with the SCECs leads to a much larger error in $\mathrm{C}_{4}{ }^{11}$ than in $\mathrm{C}_{4}{ }^{12}$ or $\mathrm{C}_{4}{ }^{13}$.

Clearly, further work is required in the determination of $\mathrm{C}_{4}{ }^{11}$. The accuracy in the ultrasonic determination of $\mathrm{C}_{4}{ }^{11}$ using the scheme described in this paper depends strongly on the selection of SCECs. The proper determination of the SCECs for the particular alloy being studied, a result that has been successfully employed in steel 

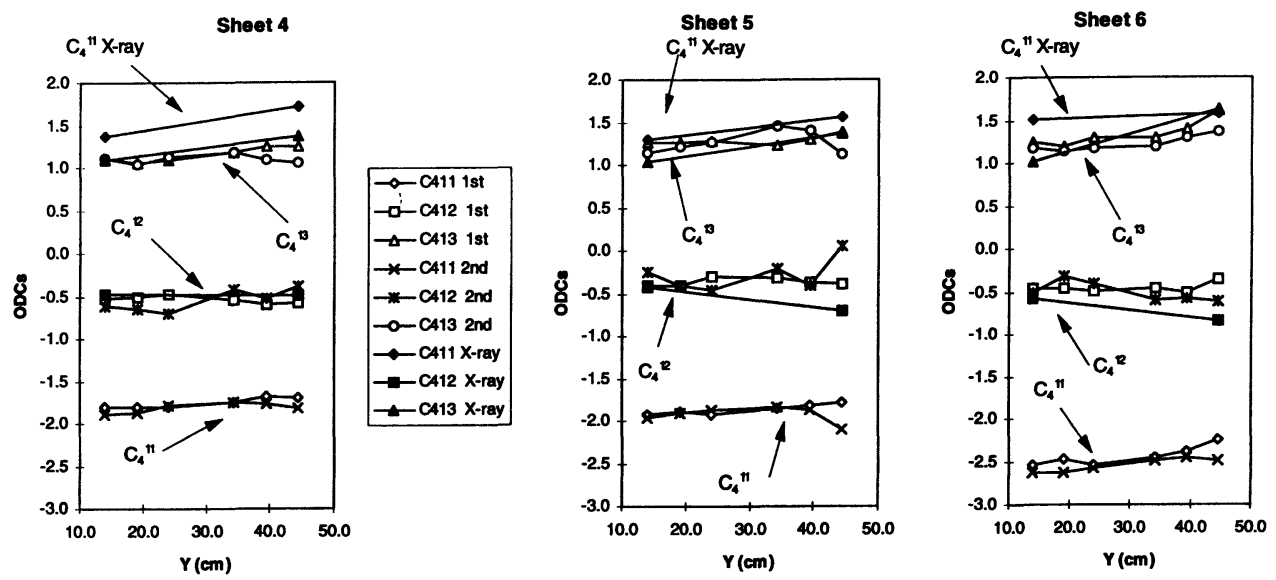

Figure 6 Spatial variations in ODCs from center of sheet to edge of sheet.

(Forouraghi, 1995; Daniel, Jonas, 1990) would presumably yield improved results and this will be the subject of further study. Other ultrasonic schemes, which infer $\mathrm{C}_{4}{ }^{11}$ from relative rather than absolute velocity measurements should also be considered ( $\mathrm{Li}$ and Thompson, 1989; Kawashima, 1990; Kawashima, Hyogushi and Akagi, 1993).

\section{DISCUSSION AND CONCLUSIONS}

Interpretation of our results is aided by knowledge of the ODCs that would be exhibited by the ideal textures present in rolled and recrystallized sheet, as are also presented in Table 4. These calculations are based on a Gaussian spread of $10^{\circ}$ about the ideal orientation. As is well known, the $\mathrm{Cu}, \mathrm{S}$ and Brass textures are typical of rolled sheet while the cube and Goss textures are typical of recrystallized sheet.

Examination of Table 4 suggests that $\mathrm{C}_{4}{ }^{13}$ should be an excellent parameter to differentiate rolling from recrystallization textures, since it has negative values of about the same magnitude for the three rolling textures and positive values of about the same values for the recrystallization textures. These values were observed in both the ultrasonic and X-ray data. The change of the angular dependence of the ultrasonic velocity shown in Figure 4 from one exhibiting a valley near $45^{\circ}$ to one with a peak near $45^{\circ}$ is a direct consequence. Figure 7 plots the values of $\mathrm{C}_{4}{ }^{13}$ determined by ultrasonics and neutron diffraction against the $\mathrm{X}$-ray values for the six samples examined, with two entries each for samples 4-6 corresponding to the center and edge positions. The good agreement suggests that this ultrasonically observable parameter could provide a useful assessment of recrystallization in field environments such as those found in rolling mills or can manufacturing plants.

Stiffler et al (1994) have also studied this possibility, reporting a correlation between degree of recrystallization and $\mathrm{C}_{4}{ }^{13}$ in $3 \mathrm{XXX}$ beverage can stock. In contrast to the present work, which utilized $\mathrm{S}_{\mathrm{o}}$ guided modes, Stiffler made measurements with $\mathrm{SH}_{\mathrm{o}}$ 


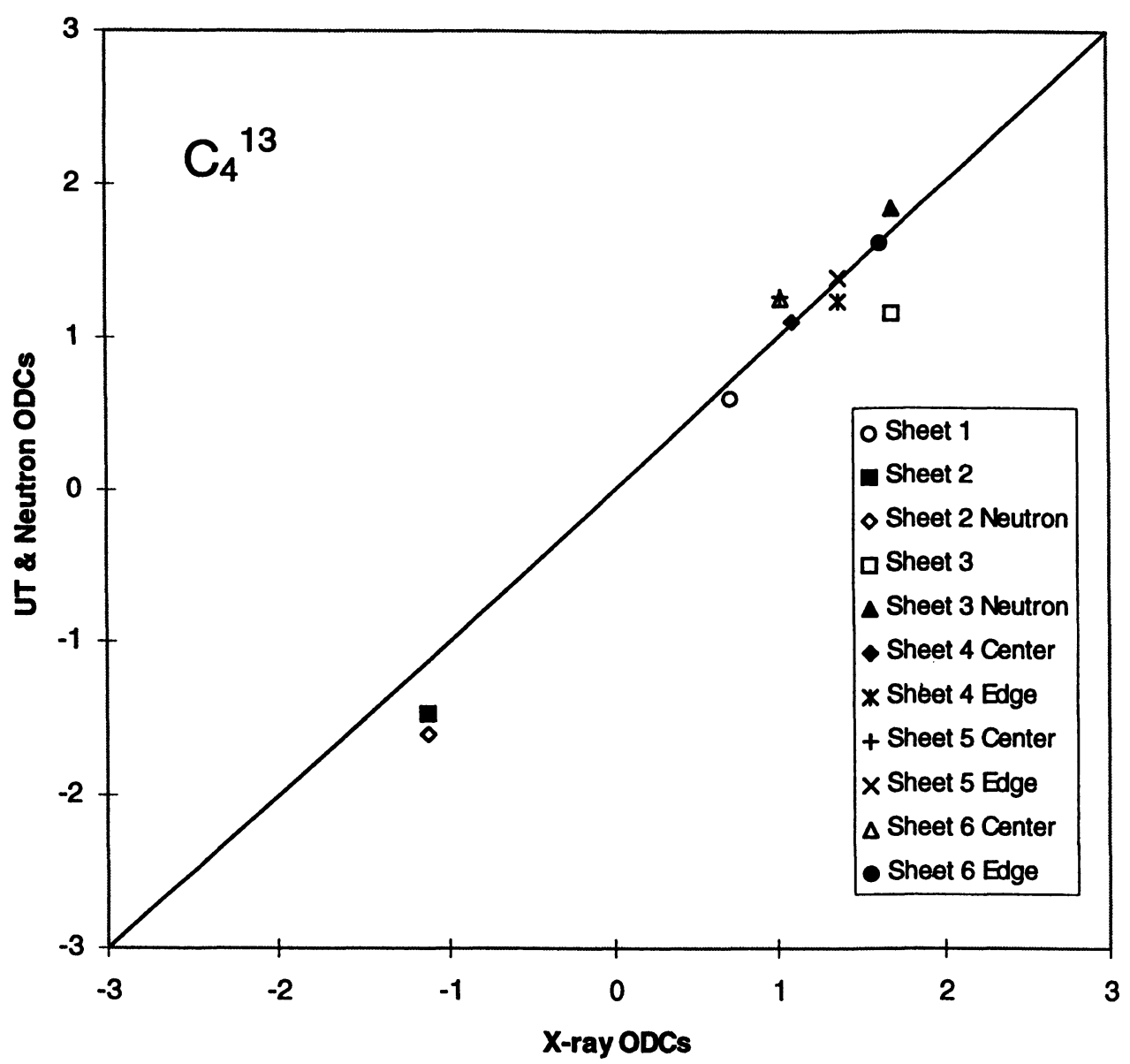

Figure 7 Comparison of $\mathrm{C}_{4}^{13}$ determined by $\mathrm{X}$-ray diffraction, ultrasonics and neutron diffraction for all six sheets.

modes. The two sets of results seem fully consistent. Stiffler's material had values of $\mathrm{C}_{4}{ }^{13}$ equal to -2.260 in the rolled condition and 1.569 in the recrystallized condition. A series of sheets whose degree of partial recrystallization was inferred from micrographs exhibited intermediate values of $\mathrm{C}_{4}{ }^{13}$ which were roughly proportional to the degree of recrystallization. The sheets studied in the present work fall in a similar range of $\mathrm{C}_{4}{ }^{13}$.

In summary, ultrasonics is a quick and precise method of characterizing texture in aluminum and aluminum alloys. Not only are strong textures differentiated, but subtle changes can be sensed as well. $\mathrm{C}_{4}{ }^{12}$ and $\mathrm{C}_{4}{ }^{13}$ can be determined precisely, and our results compare very well with other methods of determining ODCs. An important potential application of these techniques appears to be monitoring the degree of recrystallization. 


\section{Acknowledgment}

Ames Laboratory is operated for the U.S. Department of Energy by Iowa State University under Contract No. W-7405-ENG-82. This work was supported by the Director for Energy Research, Office of Basic Energy Sciences.

\section{References}

Anderson, A., Thompson, R. B., (1994). Ultrasonic Characterization of the Texture of Aluminum Alloys, In Mat'l Science Forum; Proc. ICOTOM-10, 157-162, 295.

Auld, B. A. (1973). Acoustic Fields and Waves in Solids Volume II, Wiley-Interscience, 76-88.

Borsutzki, M., Thoma, C., Bleck, W., Theiner, W. (1993). On-Line-Bestimmung von Werkstoffeigenschaften an kaltgewalztem Feinblech, In Stahl u. Eisen, 10, 93.

Bunge, H. J. (1982). Texture Analysis in Materials Science, Butterworth, Boston.

Bunge H. J. (1989). Textures and Microstructures, 10, 265.

Cassier, O., Donadille, C., Bacroix, B. (1989). Drawability Assessment of Steel Sheets by an Ultrasonic method, In Nondestr. Char. of Mat'l, Edited by P. Holler, V. Hauk, G. Dobman, C. Ruud, R. Green (Springer-Verlag, Berlin), 303.

Clark, Jr., A. V., Thompson, R. B., Li, Y., Reno, R. C., Blessing, G. V., Mitrakovic, D. V., Schamm, R. E., Matlock, D., (1990). Ultrasonic Measurement of Sheet Steel Texture and Formability: Comparison with Neutron Diffraction and Mechanical Measurements, In Res. Nondestr. Eval., 2, 239.

Clark, Jr., A. V., Reno, R. C., Thompson, R. B., Smith, J. F., Blessing, G. V., Fields, R. S., Delsanto, P. P., Mignognai, R. B. (1988). Texture Monitoring in Aluminum Alloys: A Comparison of Ultrasonic and Neutron Measurements, In Ultrasonics, 26, 189.

Clark, Jr., A. V., Berlinsky, Y., Izworski, N., Cohen, Y., Mitrakovic, D. V., Schaps, S. R. (1983). Methods to Improve the Accuracy of On-Line Ultrasonic Measurement of Sheet Steel Formability, In J. Nondestr. Eval., 12, 33.

Clark, Jr., A. V., Govada, A., Thompson, R. B., Smith, J. F., Blessing, G. V., Delsanto, P. P., Mignogma, R. B. (1987). The Use of Ultrasonics for Texture Monitoring in Aluminum Alloys, In Rev. Prog. QNDE, Edited by D. O. Thompson, D. E. Chimenti (Plenum Press, New York), 6B, 1515.

Daniel, D., Jonas, J. J. (1990). Measurement and Prediction of Plastic Anisotropy in Deep-Drawing Steels, In Met. Trans. A., 21, 331.

Forouraghi, K. (1995). Ultrasonic Measurement of Drawability (r-values) of Low Carbon Steels, Dissertation at Iowa State University.

Hirao, M., Fukuoka, H., Fujisawa, K., Murayama, R. (1989). Characterization of Formability in ColdRolled Steel Sheets Using Electromagnetic Acoustic Transducers, In Met. Trans. A, 20A, 2385.

Johnson, J. C., Thompson, R. B., (1993). The Spatial Resolution of Rayleigh Wave, Acoustoelastic Measurement of Stress, In Rev. Prog. QNDE, Edited by D. O. Thompson, D. E. Chimenti (Plenum Press, New York), 12, 2121.

Kawashima, K. (1990). Nondestructive Characterization of Texture and Plastic Strain Ratio of Metal Sheet with Electromagnetic Acoustic Transducers, In J. Acoust. Soc. Am., 87(2), 681.

Kawashima, K., Hyogushi, T., Akagi, T. (1993). On-Line Measurement of Plastic Strain Ratio of Steel Sheets Using Resonance Mode EMAT, In J. Nondestr. Eval., 12, 71.

Li, Y., Thompson, R. B., (1989). Use of the Velocity of Higher Order Lamb Modes in the Measurement of Texture, In Rev. Prog. QNDE, Edited by D. O. Thompson, D. E. Chimenti (Plenum Press, New York), 8B, 1863

Lu, W. Y., Morris, J. G., Gu, Q. (1991). Ultrasonic Measurement of the Earing Behavior of Aluminum Plate, In Rev. Prog. QNDE, Edited by D. O. Thompson, D. E. Chimenti (Plenum Press, New York), 10B, 1983.

Man, C. S., (1994). Elastic Compliance and Hill's Quadratic Yield Function for Weakly Orthotropic Sheets of Cubic Metals, In Met. Trans A., 25A, 2835.

Ren, B. (1996). Evolution of Rolling and Recrystallization Textures in a Hot Rolled Can Body Stock Alloy, In Aluminum Alloys for Packaging II, Edited by Morris, J. G., Das, S. K., Goodrich, H. S. (The Minerals, Metals \& Materials Society), 41.

Reno, R. C., Fields, R. J., Clark Jr., A. V. (1988). Crystallographic Texture in Rolled Aluminum Plates: Neutron Pole Figure Measurements, In Rev. Prog. QNDE, Edited by D. O. Thompson, D. E. Chimenti (Plenum Press, New York), 7B, 1439. 
Roe, R. (1965). Description of Crystallite Orientation in Polycrystalline Materials. III. General Solution to Pole Figure Inversion, In Journal of Applied Physics, 36, 2024.

Sayers, C. M. (1982). Ultrasonic Velocities in Anisotropic Polycrystalline Aggregates, In J. Phys. D; Appl. Phys., 15, 2157.

Stiffler, R. C., Daly, M., Wojnar, R. C. (1994). Measurement of the Degree of Recrystallization in Aluminum Sheet Using Horizontally Polarized Shear Waves, In NDE and Matl' Prop. II, edited by P.K. Liaw, O. Buck, R.J. Arsenault and R.E. Green, Jr. (The Minerals, Metals \& Materials Society) II, 161 .

Thompson, R. B., Smith J. F., Lee, S. S., Johnson, G. C. (1989). A Comparison of Ultrasonic and X-Ray Determinations of Texture in Thin $\mathrm{Cu}$ and $\mathrm{Al}$ Plates, In Met. Trans. A, 20A, 2341.

Thompson, R. B. (1990). Physical Principles of Measurement with EMAT Transducers, In Physical Acoustics, Edited by R. N. Thurston, R. D. Pierce (Academic Press, New York), XIX, 157.

Thompson, R. B., Papadakis, E. P., Bluhm, D. D., Alers, G. A., Forouraghi, K., Skank, H. D., Wormley, S. J., (1993). Measurement of Texture and Formability Parameters with a Fully Automated, Ultrasonic Instrument, In J. Nondest. Eval., 12(1), 45. 